\title{
6-minute walk distance as a predictor of outcome in idiopathic pulmonary fibrosis
}

To the Editor:

The interesting manuscript by DU BoIs et al. [1] states in the discussion section that "only two previous studies have demonstrated an independent association between 6MWD and the risk of mortality in patients with IPF", quoting the studies of CAMINATI et al. [2] and of LEDERER et al. [3].

It should be noted that in 2012 the European Respiratory Journal published a study demonstrating the significant and independent association between 6-min walk distance (6MWD) and outcome in patients newly diagnosed with idiopathic pulmonary fibrosis (IPF) [4]. In this prospective study, patients were followed for at least 3 years from the time of diagnosis. Baseline 6MWD and 6-month changes were assessed. Both 6MWD metres and 6MWD \% predicted, according to the reference equations of ENRIGHT and SHERRILL [5], were considered.

As a continuous variable, 6MWD \% predicted, but not 6MWD metres, was significantly and independently associated with 3-year mortality (HR 0.97 (95\% CI 0.96-0.99), p=0.0193 Cox proportional hazards analysis), together with the Medical Research Council dyspnoea score and the composite physiologic index [6]. With a cut-off of $72 \%$ pred, based on receiver operating characteristic analysis, $6 \mathrm{MWD} \%$ predicted was also significantly and independently associated with 3-year mortality (HR 3.27 (95\% CI 1.25-8.82), p=0.0162 Cox proportional hazards analysis) together with Medical Research Council dyspnoea score and composite physiologic index. 6MWD metres with a cut-off of $350 \mathrm{~m}$ was not a significant predictor. These results were confirmed in an independent, retrospective cohort from another centre (HR 5.43 (95\% CI 1.35-36.17), $\mathrm{p}=0.0160)$. In patients with relatively preserved exercise capacity at the time of diagnosis $(6 \mathrm{MWD}>350 \mathrm{~m}$ or $6 \mathrm{MWD}>72 \%$ pred), a 6 -month decline of either $6 \mathrm{MWD}$ meters or $6 \mathrm{MWD} \%$ predicted was also associated with significantly increased risk of mortality at 3 years after diagnosis $(p=0.038$ and $p=0.012$, respectively; $\log$ rank test) [4].

The study of DU BoIs et al. [1], selectively conducted on patients with mild-to-moderate IPF (forced vital capacity $\geqslant 55 \%$ pred, diffusing capacity of the lung for carbon monoxide $\geqslant 35 \%$ pred and $6 \mathrm{MWD}$ $\geqslant 150 \mathrm{~m}$ ) with data from the GIPF-007 (Interferon- $\gamma-1 \mathrm{~b}$ in patients with IPF) trial, provides further evidence supporting the use of 6MWD as a reliable and independent predictor of survival in IPF. It would certainly be interesting to learn about the predictive power of $6 \mathrm{MWD} \%$ predicted versus $6 \mathrm{MWD}$ metres in their study, although better reference equations are needed.

0

@ERSpublications

Both baseline 6MWD and its 6-month changes are independent predictors of survival in newly diagnosed IPF http://ow.ly/tinC6

Marco Mura

Division of Respirology, Western University, London, ON, Canada.

Correspondence: Marco Mura, London Health Science Centre, Victoria Hospital, 800 Commissioners Road East Room E6-203, N6A 5W9 London, ON, Canada. E-mail: marco.mura@lhsc.on.ca

Received: Dec 082013 | Accepted: Dec 222013

Conflict of interest: None declared.

\section{References}

du Bois RM, Albera C, Bradford WZ, et al. 6-minute walk distance is an independent predictor of mortality in patients with idiopathic pulmonary fibrosis. Eur Respir J 2014; 43: 1421-1429. 
2 Caminati AA, Bianchi R, Cassandro R, et al. Walking distance on 6-MWT is a prognostic factor in idiopathic pulmonary fibrosis. Respir Med 2009; 103: 117-123.

3 Lederer DJ, Arcasoy SM, Wilt JS, et al. Six-minute-walk distance predicts waiting list survival in idiopathic pulmonary fibrosis. Am J Respir Crit Care Med 2006; 174: 659-664.

4 Mura M, Porretta MA, Bargagli E, et al. Predicting survival in newly diagnosed idiopathic pulmonary fibrosis: a 3-year prospective study. Eur Respir J 2012; 40: 101-109.

5 Enright PL, Sherrill DL. Reference equations for the six-minute walk in healthy adults. Am J Respir Crit Care Med 1998; 158: 1384-1387.

$6 \quad$ Wells AU, Desai SR, Rubens MB, et al. Idiopathic pulmonary fibrosis: a composite physiologic index derived from disease extent observed by computed tomography. Am J Respir Crit Care Med 2003; 167: 962-969.

Eur Respir J 2014; 43: 1822-1823 | DOI: 10.1183/09031936.00213313 | Copyright @ERS 2014

\section{From the authors:}

We thank M. Mura for reminding us of the study published in the European Respiratory Journal (ERJ) in 2012 that confirmed the increasing importance of the 6-min walk test (6MWT) in the evaluation and prediction of outcome in patients suffering from idiopathic pulmonary fibrosis (IPF) [1]. In this prospective study by MURA et al. [1], of factors that predicted survival in 70 patients with newly diagnosed IPF, the major 6MWT findings were that the 6-min walk distance (6MWD) \% predicted, but not $6 \mathrm{MWD}$ defined as metres walked, was independently associated with 3-year survival, and that a receiver operating characteristic-based cut-off of $72 \%$ pred $6 \mathrm{MWD}$ best differentiated probable outcome.

By contrast, our data recently reported in the ERJ showed that both baseline and especially 24 -week change in $6 \mathrm{MWD}$, defined as metres walked, were independent predictors of outcome [2]. In our study we did not explore 6MWD \% predicted because of the reference equation concerns, referred to by M. Mura. Reference equations from healthy population-based samples using standardised 6MWT methods are not yet available [3]. The study by Mura et al. [1] used the equations that were derived from a study of 173 healthy females and 117 healthy males from Tuscon, AZ, USA [4] and, therefore, are possibly not representative of the Italian individuals who participated in their study. Given that our study included 748 patients who had enrolled in a clinical trial in 81 centres in seven European countries, the USA and Canada, we felt that it would not be appropriate to derive percent predicted values based on data from a single state in the USA. The highlights of our study were that 6MWD provided a prediction of mortality that was independent of other indices previously reported by us [5], and that the addition of 6MWD to the clinical prediction model improves model discrimination compared with the original model [2].

The findings of the study reported by MuRA et al. [1], combined with those of our own recent study [2], provide compelling evidence supporting the utility of 6MWD in both clinical practise and in designing endpoints for clinical trials of novel therapy, and reinforce the data from several earlier studies that showed favourable performance characteristics of 6MWD in patients with IPF [6-8]. Recently, this index of evaluation has appeared to have fallen out of favour but the complementary positive data provided by our study and that of MURA et al. [1] support the use of the 6MWT as a future end-point. To abandon an index prematurely would do a disservice to our patients if added value due to its continued use to predict probable outcome accrued, which would in turn be of value when considering the initiation of, or change in, therapy and the timing of referral for lung transplantation.

$\circ$

@ERSpublications

6MWD provides prediction of mortality in IPF independent of other indices previously reported to predict IPF outcome http://ow.ly/tirmb

Roland M. du Bois

Imperial College London, London, UK.

Correspondence: Roland M. du Bois, Imperial College, London, London, SW7 2AZ, UK. E-mail: ron@du-bois.co.uk

Received: Jan 042014 | Accepted: Jan 072014

Conflict of interest: Disclosures can be found alongside the online version of this article at www.erj.ersjournals.com

\section{References}

1 Mura M, Porretta MA, Bargagli E, et al. Predicting survival in newly diagnosed idiopathic pulmonary fibrosis: a 3-year prospective study. Eur Respir J 2012; 40: 101-109.

2 du Bois RM, Albera C, Bradford WZ, et al. 6-minute walk distance is an independent predictor of mortality in patients with idiopathic pulmonary fibrosis. Eur Respir J 2014; 43: 1421-1429. 